\title{
In vitro study on anti-inflammatory effects of epigallocatechin-3-gallate-loaded nano- and microscale particles
}

This article was published in the following Dove Press journal:

International Journal of Nanomedicine

22 September 2017

Number of times this article has been viewed

\author{
Yan $\mathrm{Ru} \mathrm{Wu}^{1, *}$ \\ Hong Jin $\mathrm{Choi}^{2}, *$ \\ Yun Gyeong Kang ${ }^{2}$ \\ Jeong Koo Kim ${ }^{1,2}$ \\ Jung-Woog Shin ${ }^{1-3}$ \\ 'Department of Health Science \\ and Technology, Inje University, \\ Gimhae, Gyeongnam, Republic of \\ Korea; ${ }^{2}$ Department of Biomedical \\ Engineering, Inje University, Gimhae, \\ Gyeongnam, Republic of Korea; \\ ${ }^{3}$ Cardiovascular and Metabolic \\ Disease Center, Institute of \\ Aged Life Redesign, UHARC, Inje \\ University, Gimhae, Gyeongnam, \\ Republic of Korea \\ *These authors contributed equally \\ to this work
}

Correspondence: Jung-Woog Shin; Jeong Koo Kim

Room \#309, BLDG-A, 607 Obang-Dong, Inje University, Gimhae, Gyeongnam,

62I-749, Republic of Korea

Tel +82553203317

Fax +82553273292

Email biomechshin@gmail.com; jkkim@inje.ac.kr
Purpose: This study aimed to develop an anti-inflammation system consisting of epigallocatechin-3-gallate (EGCG) encapsulated in poly(lactide-co-glycolic acid) (PLGA) particles to promote wound healing.

Methods: Nano- and microscale PLGA particles were fabricated using a water/oil/water emulsion solvent evaporation method. The optimal particle size was determined based on drug delivery efficiency and biocompatibility. The particles were loaded with EGCG. The anti-inflammatory effects of the particles were evaluated in an in vitro cell-based inflammation model.

Results: Nano- and microscale PLGA particles were produced. The microscale particles showed better biocompatibility than the nanoscale particles. In addition, the microscale particles released $\sim 60 \%$ of the loaded drug, while the nanoscale particles released $\sim 50 \%$, within 48 hours. Thus, microscale particles were selected as the carriers. The optimal EGCG working concentration was determined based on the effects on cell viability and inflammation. A high EGCG dose $(100 \mu \mathrm{M})$ resulted in poor cell viability; therefore, a lower dose $(\leq 50 \mu \mathrm{M})$ was used. Moreover, $50 \mu \mathrm{M}$ EGCG had a greater anti-inflammatory effect than $10 \mu \mathrm{M}$ concentration on lipopolysaccharide-induced inflammation. Therefore, $50 \mu \mathrm{M}$ EGCG was selected as the working dose. EGCG-loaded microparticles inhibited inflammation in human dermal fibroblasts. Interestingly, the inhibitory effects persisted after replacement of the drug-loaded particle suspension solution with fresh medium.

Conclusion: The EGCG-loaded microscale particles are biocompatible and exert a sustained anti-inflammatory effect.

Keywords: wound healing, anti-inflammation, EGCG, microparticles, carriers

\section{Introduction}

Nonhealing wounds, including acute wounds and chronic wounds, affect millions of patients in the US annually and are associated with health care costs of over US\$25 billion. ${ }^{1}$ Impaired wound healing is generally caused by pathological inflammation due to infection or endotoxin. Without effective decontamination, the presence of bacteria and/or endotoxin increases the expression of proinflammatory factors, such as tumor necrosis factor alpha (TNF- $\alpha$ ), interleukin (IL) $1 \beta$, and IL-6, and prolongs inflammation, which leads to abnormal healing. ${ }^{2}$ Therefore, anti-inflammation systems can be used for the early treatment of wounds.

Epigallocatechin-3-gallate (EGCG), an antioxidant and anti-inflammatory reagent, is the major polyphenol component of green tea. EGCG inhibits inflammation mediated by various cell types, such as immune cells, vascular endothelial cells, and fibroblasts. ${ }^{3-5}$ In addition, it was reported that H-bonding between EGCG and polymers helps EGCG to 
be bonded to polymers. ${ }^{6}$ Fibroblasts are the predominant cell type in mammalian skin. Furthermore, EGCG significantly improves initial epithelial neoformation, ${ }^{7}$ angiogenesis, and wound contraction; ${ }^{8}$ thus, it shows promise for enhancing wound healing. However, the effectiveness of EGCG is dose dependent, and most studies recommend a dose of $<100 \mu \mathrm{M}$. ${ }^{9}$ The optimal dose of EGCG according to indication must be determined.

Controlled drug delivery/release systems, which consist of a drug and its carrier, are currently used to treat wounds. ${ }^{10}$ Various biocompatible, biodegradable polymers in the form of nano- or microscale particles are used as carriers in such systems. ${ }^{11}$ The size of the particles is related to their toxicity in a manner dependent on the cell type in question. ${ }^{12}$

In this study, we developed an EGCG-loaded particle system for the treatment of inflammation in wound healing. EGCG was encapsulated inside the particles, and this encapsulation prevents its oxidation and maintains its bioactivity. Encapsulation also controls the rate of continuous drug release. This system has promise as a functional dressing for the treatment of nonhealing wounds.

\section{Materials and methods}

\section{Fabrication and visualization of particles}

Poly(lactic-co-glycolic acid) (PLGA; 50:50, relative molecular weight $=24,000-38,000$; Sigma-Aldrich Co., St Louis, MO, USA) particles were prepared by a water/ oil/water emulsion solvent evaporation method. ${ }^{13,14}$ Briefly, $10 \mathrm{mg}$ PLGA was dissolved in $1 \mathrm{~mL}$ dichloromethane (Junsei Chemical, Tokyo, Chuo-ku, Japan), and 1 mg EGCG (SigmaAldrich Co.) in $1 \mathrm{~mL}$ distilled water was added to this solution to generate EGCG-loaded particles. Next, $0.7 \mathrm{wt} \%$ of the surfactant solvent polyvinyl alcohol (relative molecular weight $=13,000-23,000$; Sigma-Aldrich Co.) was added. The solution was irradiated for 5 minutes using an ultrasound homogenizer or stirred for 24 hours using a magnetic stir bar to generate nano- or microscale particles, respectively. Particles were then rinsed several times in distilled water, lyophilized for 48 hours, and stored at $-70^{\circ} \mathrm{C}$. EGCG is known to be sensitive to temperature and light. ${ }^{6,15,16}$ Therefore, EGCG has been always protected from light during storage and loading into particles. Also, EGCG was kept in a bottle wrapped with aluminum foil at $4^{\circ} \mathrm{C}$ or lower.

The fabricated PLGA particles were visualized using a field emission scanning electron microscope (SEM; Hitachi Ltd., Tokyo, Japan). The particle size distribution was evaluated by dynamic light scattering (Malvern Instruments, Malvern, UK).

\section{Cell preparation}

Human dermal fibroblasts (ATCC, Manassas, VA, USA) were cultured in Dulbecco's Modified Eagle's Medium (Thermo Fisher Scientific, Waltham, MA, USA) supplemented with $1 \%$ penicillin/streptomycin (GE Healthcare Life Sciences, Logan, UT, USA) and 10\% fetal bovine serum (Thermo Fisher Scientific). The cells were incubated at $37^{\circ} \mathrm{C}$ with $5 \% \mathrm{CO}_{2}$ in an incubator until further use.

\section{Experimental conditions}

\section{Determination of the particle size}

To determine the proper particle size, 3-(4,5-dimethylthiazol2-yl)-2,5-diphenyltetrazolium bromide (MTT; Hoffman-La Roche Ltd., Basel, Switzerland) assays and EGCG release tests were performed. For MTT assay, cells were seeded in 96-well plates at $1 \times 10^{4} / \mathrm{cm}^{2}$. After 24 hours, two types of particles (nano- or microscale) at 10, 25, 50, 100, and $200 \mu \mathrm{g} / \mathrm{mL}$ concentrations were added to the cultured cells and incubated for 24 hours. MTT labeling reagent was then added to the cells, followed by incubation for 4 hours at $37^{\circ} \mathrm{C}$ in $5 \% \mathrm{CO}_{2}$. Solubilization solution was added to the cells for 12 hours to dissolve the crystals. The optical density at $595 \mathrm{~nm}$ was measured in each well using a microplate spectrophotometer.

For the selection of particle size, drug-release tests were performed. EGCG-loaded particles ( $2 \mathrm{mg}$ ) were dispersed in $10 \mathrm{~mL}$ phosphate-buffered saline and incubated at $37^{\circ} \mathrm{C}$ with shaking. The absorbance of a mixture $(1.0 \mathrm{~mL})$ of the supernatant and acetonitrile/water $(70: 30, \mathrm{v} / \mathrm{v})$ was determined after $4,8,12,24$, and 48 hours using a UV-vis spectrometer. EGCG levels were determined based on the maximum absorption peak at $285 \mathrm{~nm}$ and absorption wavelength at 248-328 nm. The efficiency of release was expressed as the percentage of EGCG released compared with the amount loaded.

\section{Determination of the optimal EGCG concentration}

To evaluate the cytotoxicity induced by EGCG, fibroblasts were seeded in 96 -well plates at $1 \times 10^{4} / \mathrm{cm}^{2}$. After 24 hours, EGCG $(0,10,25,50$, or $100 \mu \mathrm{M})$ was added to the cells and incubated for 24 hours. Cell viability was evaluated by MTT assay based on the optical density at $595 \mathrm{~nm}$.

Anti-inflammatory activity was evaluated in vitro in a cell-based model of inflammation using $100 \mathrm{ng} / \mathrm{mL}$ lipopolysaccharide (LPS; Sigma-Aldrich Co.). After treatment with EGCG $(0,10$, or $50 \mu \mathrm{M})$ for 24 hours, cells were pelleted by centrifugation. Total mRNA was extracted from the cell 
Table I Inflammatory gene primers used for RT-PCR

\begin{tabular}{|c|c|c|}
\hline Gene & $\begin{array}{l}\text { Accession } \\
\text { number }\end{array}$ & Primer sequence \\
\hline \multirow[t]{2}{*}{ TNF- $\alpha$} & NM_000594.3 & Forward $5^{\prime}$ TCCTTCAGACACCCTCAACC $3^{\prime}$ \\
\hline & & Reverse 5'AGGCCCCAGTTTGAATTCTT3' \\
\hline \multirow[t]{2}{*}{ IL-I $\beta$} & NM_000576.2 & Forward 5'ACAGGCTGCTCTGGGATTCT3' \\
\hline & & Reverse 5'TGAAGCCCTTGCTGTAGTGG3' \\
\hline \multirow[t]{2}{*}{ IL-6 } & NM_000600.4 & Forward 5'CCAGTACCCCCAGGAGAAGA3' \\
\hline & & Reverse 5'TTGTTTTCTGCCAGTGCCTC3' \\
\hline
\end{tabular}

Abbreviations: TNF- $\alpha$, tumor necrosis factor-alpha; IL-I $\beta$, interleukin- I beta; IL-6, interleukin-6; RT-PCR, reverse transcription polymerase chain reaction.

pellet using the RNeasy Mini Kit (Qiagen, Hilden, Germany), and cDNA was generated using the High-Capacity RNAto-cDNA Kit (Thermo Fisher Scientific). TNF- $\alpha$, IL-1 $\beta$, IL-6, and $\beta$-actin mRNA levels were analyzed by realtime polymerase chain reaction (RT-PCR) (Table 1). The RT-PCR conditions were as follows: 10 minutes at $95^{\circ} \mathrm{C}$ for the initial denaturation, followed by 40 cycles of 15 seconds at $95^{\circ} \mathrm{C}, 30$ seconds at $58^{\circ} \mathrm{C}$, and 30 seconds at $72^{\circ} \mathrm{C}$. A melting curve analysis was performed following amplification. mRNA levels were determined according to the ${ }^{\Delta \Delta} \mathrm{CT}$ method.

\section{Effects of the EGCG-loaded particles}

The drug loading/release assay indicated that $\sim 400 \mu \mathrm{g} / \mathrm{mL}$ EGCG-loaded microparticles are required for release of $50 \mu \mathrm{M}$ EGCG. Therefore, the biocompatibility of $400 \mu \mathrm{g} / \mathrm{mL}$ EGCG microparticles was evaluated at 24 hours by MTT assay.

The anti-inflammatory activity of the particles was assessed by RT-PCR in two groups: the EGCG microparticletreated group (LPS + EM, $400 \mu \mathrm{g} / \mathrm{mL}$ EGCG and $100 \mathrm{ng} / \mathrm{mL}$ LPS) and the LPS control group (100 ng/mL LPS). The levels of TNF- $\alpha$, IL- $1 \beta$, and IL- 6 were determined, and the results were expressed as the percentage expression in the LPS + EM group to that in the LPS control group.

To assess the duration of the induced anti-inflammatory activity after removal of the drug-loaded particles, the medium containing LPS with or without EGCG microscale particles was replaced with fresh medium. After 8 hours of incubation, TNF- $\alpha$, IL-1 $\beta$, and IL-6 expression was determined.

\section{Statistical analysis}

Differences were subjected to one-way analysis of variance using SPSS version 19.0K software (SPSS Inc., Chicago, IL, USA). A value of $P<0.05$ was considered to indicate statistical significance.

\section{Results}

\section{Visualization of the fabricated particles}

SEM images of the fabricated nano- and microscale particles are shown in Figure $1 \mathrm{~A}(\times 5,000)$ and $\mathrm{B}(\times 1,000)$. Most of the nanoscale particles were less than $1 \mu \mathrm{m}$ in diameter (Figure 1C), while the microscale particles ranged from 1 to $20 \mu \mathrm{m}$ in diameter (Figure 1D).

\section{Efficacy of the microscale particles as drug carriers: biocompatibility and drug release}

The results of MTT assays of cells exposed to the particles without EGCG are shown in Figure 2A and B. Almost more than half of the cells were damaged by the nanoscale particles, irrespective of the concentration. However, most cells survived treatment with the microscale particles, irrespective of the concentration. There was no concentration equivalent to IC50 in the range of application when microscale particles were used. But when nanoscale particles were introduced, IC50 can be estimated as $\sim 50 \mu \mathrm{g} / \mathrm{mL}$.

EGCG release from the nanoscale and microscale particles is shown in Figure $2 \mathrm{C}$ and D. Almost $60 \%$ of the EGCG was released from the microscale particles by 12 hours; no additional release was observed thereafter. In contrast, $<40 \%$ of the EGCG was released from the nanoscale particles in 12 hours.

\section{EGCG exerts dose-dependent cytotoxic and anti-inflammatory effects}

The effect of EGCG $(0-100 \mu \mathrm{M})$ on fibroblasts was evaluated by MTT assay at 24 and 72 hours (Figure 3A; $n=6$ ). Cell proliferation tended to decrease with increasing EGCG concentration, and this effect was enhanced after 72 hours. These results suggest that high doses of EGCG inhibit fibroblast growth; therefore, $\leq 50 \mu \mathrm{M}$ doses of EGCG were evaluated. The effects of $\leq 50 \mu \mathrm{M}$ EGCG on inflammation in fibroblasts after 24 hours were verified by RT-PCR (Figure 3B; n=3). A greater anti-inflammatory effect was exerted by $50 \mu \mathrm{M}$ than by $10 \mu \mathrm{M}$ EGCG. Based on these results, microscale particles were loaded with $50 \mu \mathrm{M}$ EGCG for subsequent experiments.

\section{Sustained anti-inflammatory effect of EGCG-loaded microparticles}

The anti-inflammatory effects of EGCG-loaded microparticles on LPS-treated fibroblasts were assessed by determining the expression levels of TNF- $\alpha$, IL- $1 \beta$, and IL- 6 at 24 hours, 
A

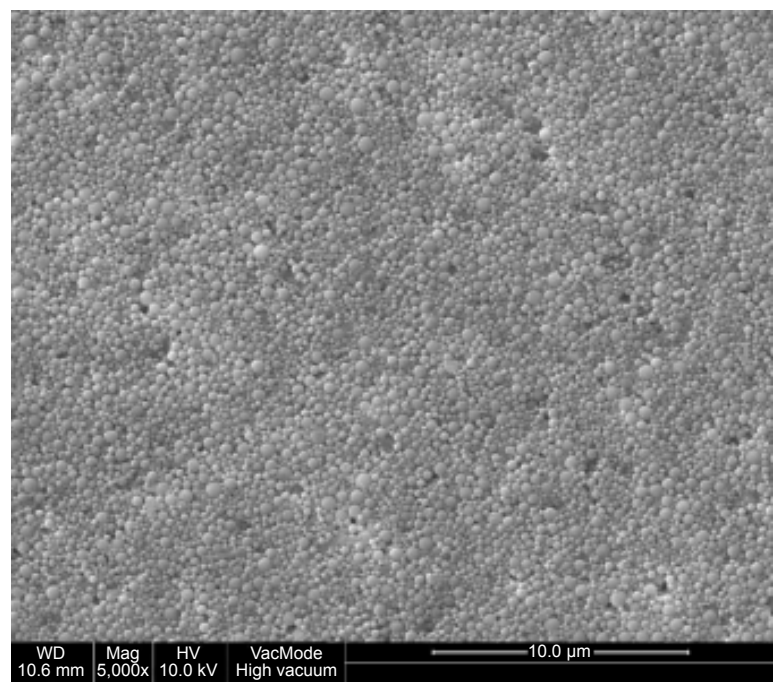

C

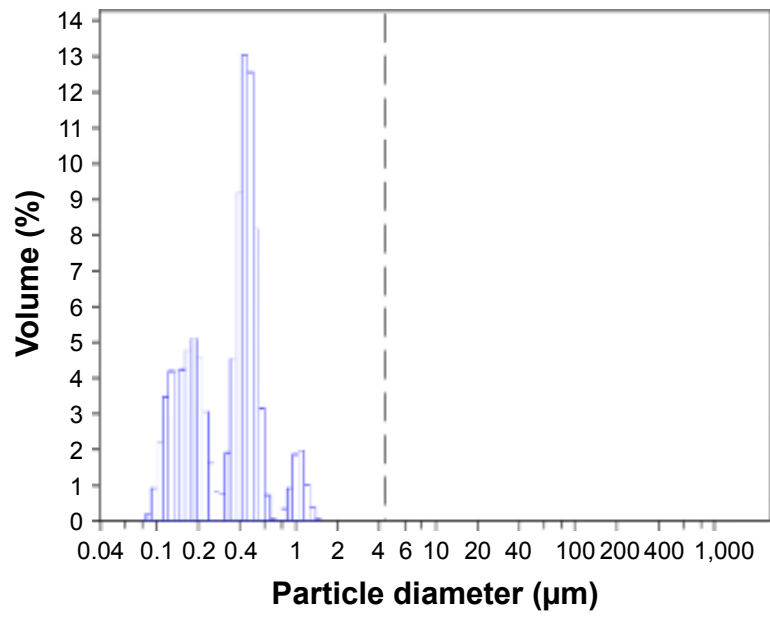

B

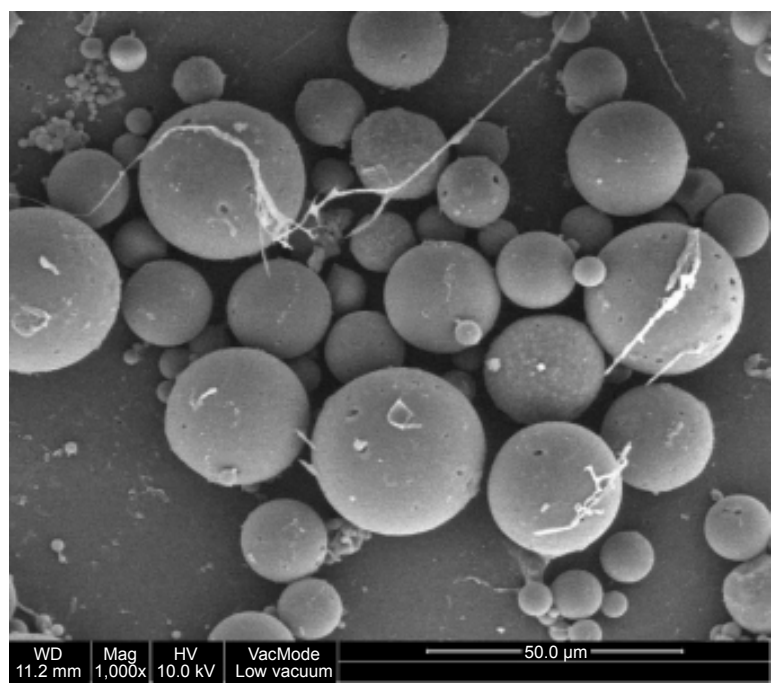

D

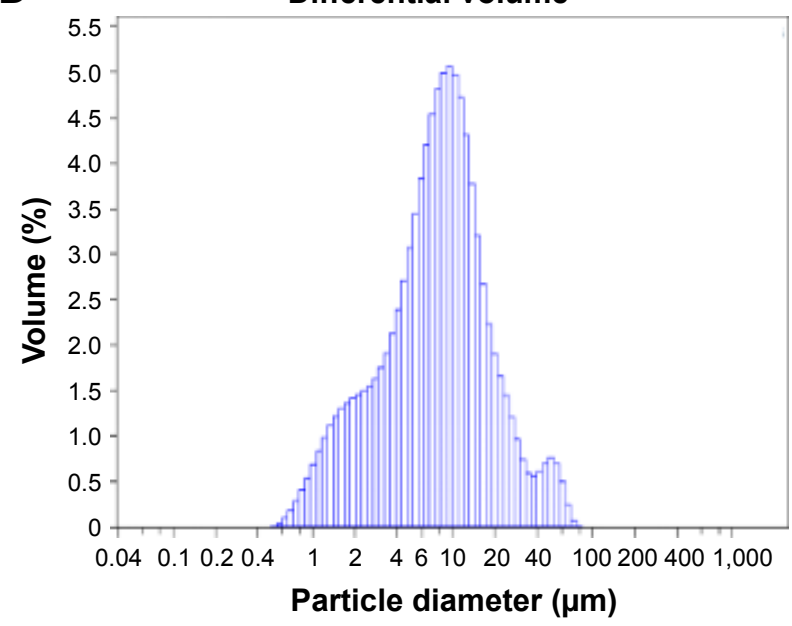

Figure I Scanning electron microscopy images $(\mathbf{A}$ and $\mathbf{B})$ and dynamic light scattering results $(\mathbf{C}$ and $\mathbf{D})$ of PLGA particles. Morphologies of the $(\mathbf{A})$ nanoscale $(\times 5,000)$ and (B) microscale $(\times I, 000)$ particles. Size distributions of the $(\mathbf{C})$ nanoscale and $(\mathbf{D})$ microscale particles.

Abbreviation: PLGA, poly(lactide-co-glycolic acid).

and again at 8 hours after replacing the microscale particleloaded medium with fresh medium. The expression of TNF- $\alpha$ and IL- 6 , but not IL-1 $\beta$, was significantly decreased at 24 hours after administration of the EGCG-loaded microparticles (Figure 4A). TNF- $\alpha$, IL- $1 \beta$, and IL-6 expression was significantly decreased at 8 hours after medium replacement (Figure 4B). Therefore, the EGCG-loaded microparticles exerted a sustained anti-inflammatory effect.

\section{Discussion}

The aim of this study was to develop an anti-inflammation system to suppress the inflammation associated with wounding. The proposed system consists of EGCG encapsulated in biodegradable/nontoxic PLGA particles, which continuously release EGCG.
The effect of particle size on drug delivery and/or release has been investigated extensively. Particles $<10 \mu \mathrm{m}$ in diameter are phagocytized by immune cells, leading to the loss of the encapsulated drug. ${ }^{17}$ In contrast, particles $>200 \mu \mathrm{m}$ in diameter induce immune and inflammatory reactions. ${ }^{17}$ In addition, drug delivery/release efficiency is influenced by particle size, shape, stiffness, and degradation rate. ${ }^{18,19}$ Spherical particles have the greatest diameter-to-surface area ratio. We did not assess the effect of stiffness, as the particles used in this study will be applied to the skin. Drug release assays were conducted up to 48 hours to mimic real-world conditions, ie, changing of wound dressings at $<24$-hour intervals. The microscale particles released more than half of the encapsulated EGCG within 12 hours, with no significant release thereafter. This suggests that a significant proportion 

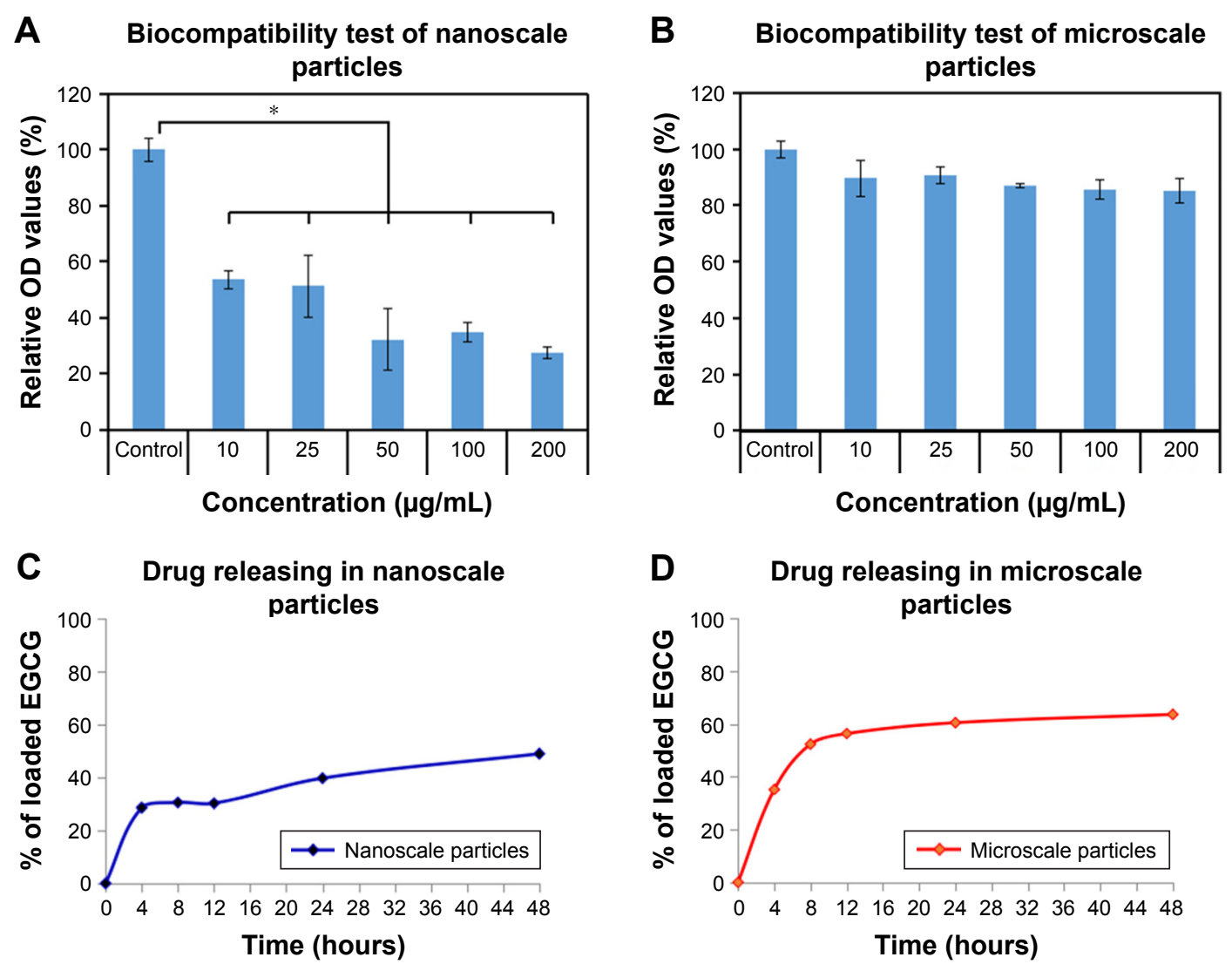

Figure 2 Effects of EGCG on cell viability and the pattern of drug release. Relative optical density values of the $(\mathbf{A})$ nanoscale and $(\mathbf{B})$ microscale particles. Drug release from (C) nanoscale and (D) microscale particles $(n=3) ; * P<0.05$.

Abbreviation: EGCG, epigallocatechin-3-gallate.

of the PLGA particles were degraded within 8 hours. When PLGA is prepared in the form of volumetric structure or mixed with other materials, it usually needs 8 weeks or more to be degraded. ${ }^{20,21}$ In other previous studies, $50 \%-80 \%$ of the encapsulated drug was released within less than 12 hours upon bursting of the PLGA particles. ${ }^{22,23}$ In this study, the amount of released EGCG was calculated and expressed as a percentage of the amount added during the initial particle preparation. This percentage is expected to be high if based on the actual amount of the EGCG encapsulated. However, the purpose of this experiment was to identify the drug release pattern in terms of the timing of the drug release
A

Cell toxicity of EGCG

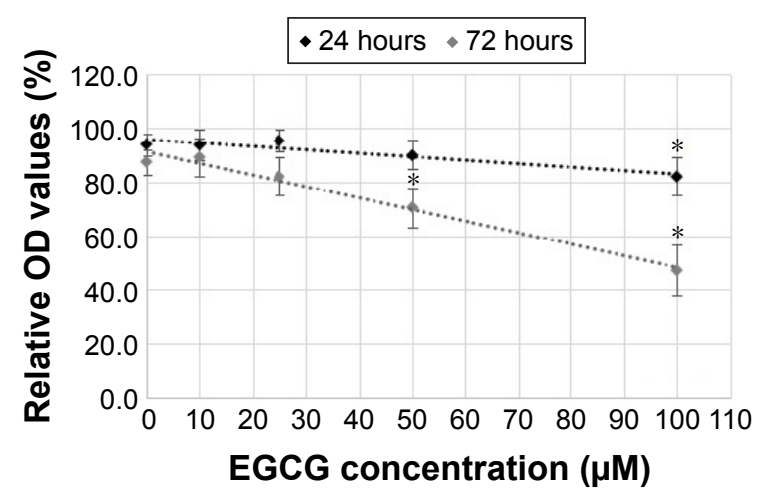

B

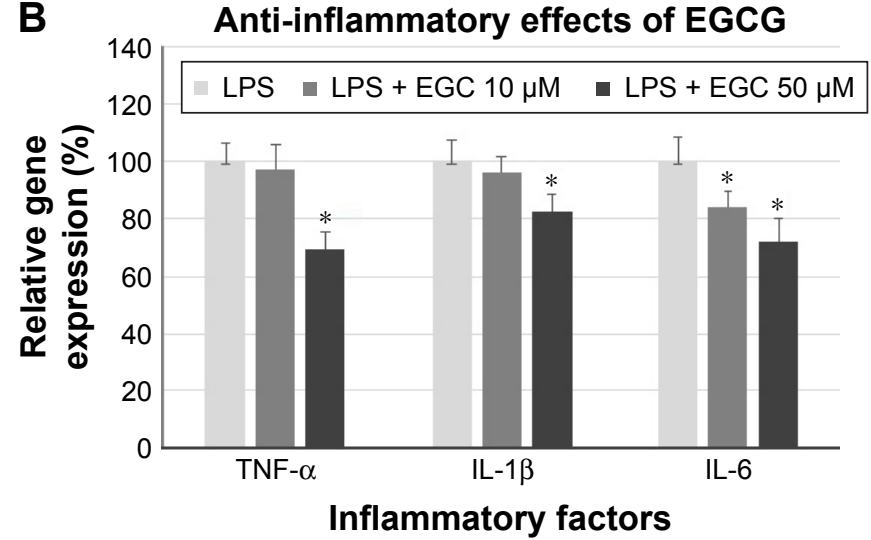

Figure 3 Effects of various concentrations of EGCG on (A) cell viability of intact fibroblasts $(n=6)$ and $(\mathbf{B})$ anti-inflammation in LPS-induced inflammatory fibroblasts as determined by RT-PCR $(n=3) ; * P<0.05$.

Abbreviations: EGCG, epigallocatechin-3-gallate; IL-I $\beta$, interleukin-I beta; IL-6, interleukin-6; LPS, lipopolysaccharide; OD, optical density; RT-PCR, reverse transcription polymerase chain reaction; TNF- $\alpha$, tumor necrosis factor-alpha. 
A

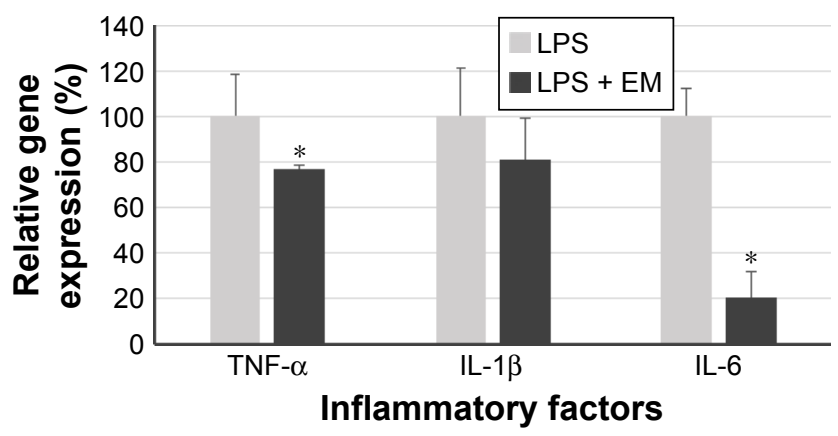

B Follow up effects of EGCG microparticles

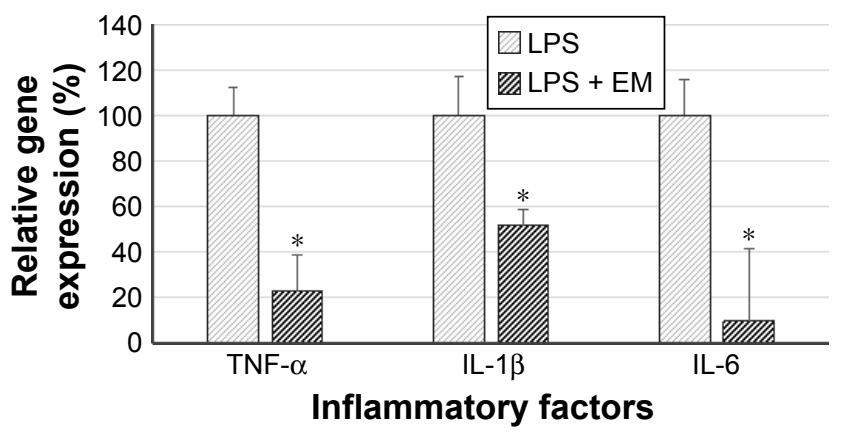

Figure 4 Acute and sustained anti-inflammatory effects of EGCG-loaded microparticles as determined by RT-PCR. (A) Acute effects ( $\mathrm{n}=3$ ) and (B) sustained effects after medium replacement $(n=3) ; * P<0.05$.

Abbreviations: EGCG, epigallocatechin-3-gallate; RT-PCR, reverse transcription polymerase chain reaction; LPS, lipopolysaccharide; EM, EGCG microparticle; TNF- $\alpha$, tumor necrosis factor-alpha; IL-I $\beta$, interleukin-I beta; IL-6, interleukin-6.

and the point at which it was no longer released. Therefore, a sufficient quantity of EGCG was considered to be released from the loaded microscale particles within 12 hours, as most wound dressings are recommended to be replaced within less than 24 hours.

EGCG has potential for treatment of a broad range of diseases, such as diabetes, hypertension, and neurological diseases, based on its anti-inflammatory and antioxidant effects. ${ }^{8,24,25}$ However, our results (Figure 3A) suggested that EGCG has poor bioavailability when applied at high concentrations. An EGCG concentration $>100 \mu \mathrm{M}$ reportedly causes oxidative DNA damage and increases $\mathrm{H}_{2} \mathrm{O}_{2}$ production, while $>200 \mu \mathrm{M}$ EGCG affects cell-cycle progression. ${ }^{26}$ Therefore, the applied dose of EGCG should be carefully controlled. In this study, $50 \mu \mathrm{M}$ EGCG was used to treat inflammation; this is a safe concentration based on the viability test. The EGCG-loaded microparticles suppressed the expression of TNF- $\alpha$, IL-1 $\beta$, and IL- 6 at 24 hours (Figure 4A). Moreover, TNF- $\alpha$, IL-1 $\beta$, and IL-6 expression was significantly reduced at 8 hours after medium replacement (Figure 4B).

This study had several limitations. We did not investigate the effects of our system on wound healing processes such as migration, neoformation, or angiogenesis. However, a previous animal study demonstrated that EGCG improved epithelial neoformation, from $27.32 \%$ (vehicle control) to $48.20 \%$ (EGCG). ${ }^{7}$ Furthermore, enhancements of angiogenesis and granulation tissue formation in vivo by EGCG have been reported. ${ }^{8}$ To our knowledge, no study has evaluated the effects of EGCG-loaded PLGA particles on healing. Therefore, further research in animal models is warranted.

In conclusion, EGCG-loaded microscale particles inhibited inflammation, and this effect was sustained even after removal of the drug.

\section{Acknowledgment}

This work was supported by the Human Resource Training Program for Regional Innovation and Creativity through the Ministry of Education and National Research Foundation of Korea (NRF-2014H1C1A1073148).

\section{Disclosure}

The authors report no conflicts of interest in this work.

\section{References}

1. Sen CK, Gordillo GM, Roy S, et al. Human skin wounds: a major and snowballing threat to public health and the economy. Wound Repair Regen. 2009;17(6):763-771.

2. Avishai E, Yeghiazaryan K, Golubnitschaja O. Impaired wound healing: facts and hypotheses for multi-professional considerations in predictive, preventive and personalised medicine. EPMA J. 2017;8(1):23.

3. Zhong Y, Chiou YS, Pan MH, et al. Anti-inflammatory activity of lipophilic epigallocatechin gallate (EGCG) derivatives in LPS-stimulated murine macrophages. Food Chem. 2012;134(2):742-748.

4. Yang J, Han Y, Chen C, et al. EGCG attenuates high glucose-induced endothelial cell inflammation by suppression of PKC and NF- $\mathrm{KB}$ signaling in human umbilical vein endothelial cells. Life Sci. 2013; 92(10):589-597.

5. Jung IH, Lee DE, Yun JH, et al. Anti-inflammatory effect of (-)-epigallocatechin-3-gallate on Porphyromonas gingivalis lipopolysaccharidestimulated fibroblasts and stem cells derived from human periodontal ligament. Journal Periodontal Implant Sci. 2012;42(6):185-195.

6. Peter B, Farkas E, Forgacs E, et al. Green tea polyphenol tailors cell adhesivity of RGD displaying surfaces: multicomponent models monitored optically. Sci Rep. 2017;7:42220.

7. Neves ALA, Komesu MC, Matteo MASD. Effects of green tea use on wound healing. Int J Morphol. 2010;28(3):905-910.

8. Kim HH, Kawazoe T, Han DW, et al. Enhanced wound healing by an epigallocatechin gallate-incorporated collagen sponge in diabetic mice. Wound Repair Regen. 2008;16(5):714-720.

9. Chen LL, Han WF, Geng Y, et al. A genome-wide study of DNA methylation modified by epigallocatechin-3-gallate in the CAL-27 cell line. Mol Med Rep. 2015;12(4):5886-5890.

10. Gainza G, Villullas S, Pedraz JL, et al. Advances in drug delivery systems (DDSs) to release growth factors for wound healing and skin regeneration. Nanomedicine. 2015;11(6):1551-1573.

11. Kumar M. Nano and microparticles as controlled drug delivery devices. J Pharm Pharm Sci. 2000;3(2):234-258. 
12. Sohaebuddin SK, Thevenot PT, Baker D, et al. Nanomaterial cytotoxicity is composition, size, and cell type dependent. Part Fibre Toxicol. 2010;7(1):22.

13. McCall RL, Sirianni RW. PLGA nanoparticles formed by single-or double-emulsion with vitamin E-TPGS. J Vis Exp. 2013;(82):51015.

14. Chi NT, Triet NM, Chien DM. Preparation of drug nanoparticles by emulsion evaporation method. JPCS. 2009;187(1):012047.

15. Peter B, Bosze S, Horvath R. Biophysical characteristics of proteins and living cells exposed to the green tea polyphenol epigallocatechin-3gallate (EGCg): review of recent advances from molecular mechanisms to nanomedicine and clinical trials. Eur Biophys J. 2017;46(1):1-24.

16. Fang Z, Bhandari B. Encapsulation of polyphenols-a review. Trends Food Sci Technol. 2010;21(10):510-523.

17. Dawes GJS, Fratila-Apachitei LE, Mulia K, et al. Size effect of PLGA spheres on drug loading efficiency and release profiles. J Mater Sci Mater Med. 2009;20(5):1089-1094.

18. Sen Gupta A. Role of particle size, shape, and stiffness in design of intravascular drug delivery systems: insights from computations, experiments, and nature. Wiley Interdiscip Rev Nanomed Nanobiotechnol. 2016 8(2):255-270.

19. Coelho JF, Ferreira PC, Alves P, et al. Drug delivery systems: advanced technologies potentially applicable in personalized treatments. EPMAJ. 2010;1(1):164.
20. Choi HJ, Lee JJ, Park YJ, et al. MG-63 osteoblast-like cell proliferation on auxetic PLGA scaffold with mechanical stimulation for bone tissue regeneration. Biomater Res. 2016;20(1):33.

21. Lanao RPF, Leeuwenburgh SCG, Wolke JGC, et al. In vitro degradation rate of apatitic calcium phosphate cement with incorporated PLGA microspheres. Acta Biomater. 2011;7(9):3459-3468.

22. Bohr A, Kristensen J, Dyas M, et al. Release profile and characteristics of electrosprayed particles for oral delivery of a practically insoluble drug. J R Soc Interface. 2012;9(75):2437-2449.

23. Zhao J, Guo B, Ma PX. Injectable alginate microsphere/PLGA-PEGPLGA composite hydrogels for sustained drug release. RSC Adv. 2014; 4(34):17736-17742.

24. Bogdanski P, Suliburska J, Szulinska M, et al. Green tea extract reduces blood pressure, inflammatory biomarkers, and oxidative stress and improves parameters associated with insulin resistance in obese, hypertensive patients. Nutr Res. 2012;32(6):421-427.

25. Lee H, Bae JH, Lee SR. Protective effect of green tea polyphenol EGCG against neuronal damage and brain edema after unilateral cerebral ischemia in gerbils. J Neurosci Res. 2004;77(6):892-900.

26. Sugisawa A, Umegaki K. Physiological concentrations of (-)-epigallocatechin-3-O-gallate (EGCg) prevent chromosomal damage induced by reactive oxygen species in WIL2-NS cells. J Nutr. 2002;132(7): 1836-1839.
International Journal of Nanomedicine

\section{Publish your work in this journal}

The International Journal of Nanomedicine is an international, peerreviewed journal focusing on the application of nanotechnology in diagnostics, therapeutics, and drug delivery systems throughout the biomedical field. This journal is indexed on PubMed Central,

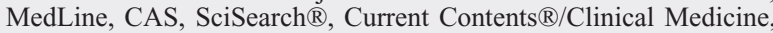

\section{Dovepress}

Journal Citation Reports/Science Edition, EMBase, Scopus and the Elsevier Bibliographic databases. The manuscript management system is completely online and includes a very quick and fair peer-review system, which is all easy to use. Visit http://www.dovepress.com/ testimonials.php to read real quotes from published authors. 